\title{
Physiological characterization of Jasmine flower (Jasminum sambac) senescence during storage
}

\author{
V. Lavanya, ${ }^{*}$ Udaykumar Nidoni $^{1}$, B. Kisan ${ }^{2}$, H. Amarananjundeshwara, and V. Ramya \\ ${ }^{1}$ Department of Processing and Food Engineering, College of Agricultural Engineering, University of Agricultural \\ Sciences, Raichur (Karnataka), INDIA \\ ${ }^{2}$ Department of Genetics and Plant Breeding, Main Agricultural Research Station, College of Agriculture, \\ University of Agricultural Sciences, Raichur (Karnataka), INDIA \\ ${ }^{3}$ Department of Horticuture, College of Agriculture, Kolar (Karnataka), INDIA \\ *Corresponding author. E-mail: 90.lavanya@gmail.com
}

Received: January 22, 2016; Revised received: May 28, 2016; Accepted: August 05, 2016

\begin{abstract}
The aim of this work was to identify metabolic differences and hormonal profiles in jasmine flower (Jasminum sambac) and to investigate the possibility that experimental promotion of retardation of the senescence of jasmine flower may mediated by abscisic acid (ABA) and phenolic content. Determinations of ABA and phenols were made in flower senescing under different conditions using two different packaging materials such as polyethylene (PE) and polypropylene (PP) of 200 gauge micron thickness with no ventilation. Pre-treatment of $4 \%$ boric acid for jasmine flowers was selected. Abscisic acid levels in petals also increased during senescence $91.27 \mathrm{pmol} \mathrm{g}^{-1}$, but much less in boric acid-treated jasmine flower $34.16 \mathrm{pmol} \mathrm{g}^{-1}$. However, the lowest content of total phenolics was measured in buds and partially opened flowers $50.90 \mu \mathrm{g} / \mathrm{g}$ but highest in fully opened $61.80 \mu \mathrm{g} / \mathrm{g}$ on the fourth day of storage, respectively. It was concluded that boric acid prevented the early rise in ethylene production and considerably improved jasmine flower shelf-life.
\end{abstract}

Keywords: Abscisic acid (ABA), Boric acid, Jasminum sambac, Packaging material, Total phenols

\section{INTRODUCTION}

Jasmine, the queen of flowers is a popular fragrant flower, which is highly perishable of nature with a limited shelf life. The flower buds are widely used in garlands, for worshiping and hair decoration ornaments by Indian women and other Eastern countries. Jasmine (Jasminum sambac) belongs to the family "oleaceae", which is one of the oldest fragrant flowers cultivated by humans and known to be the native of subtropical regions and taken to other parts of the globe. Jasmine is the national flower of the Philippines adopted by its government in 1937 and in 1990, Indonesian government across the world, adopted as the national flower. Although more than 2,000 species are known, 40 species have been identified in India, and 20 species are cultivated in South India. Jasminum sambac commonly known as Motia or lily jasmine is a scandent or sub-erect shrub with young pubescent branches, broadly ovate or elliptic, opposite leaves, white, very fragrant flowers cultivated nearly throughout the tropical and sub-tropical parts of the world (Kiritikar et al., 2003). The best known species among jasmines is $J$. sambc and several varieties of this species viz., Arabian or Tuscan. In India, jasmines are cultivated throughout the country. However, the largest area under Jasmine flower production is in Tamil Nadu followed by Karnataka. The annual production of flowers in India is worth more than ' 120 million (Dadlani, 2004). In Karnataka, the jasmine flower cultivation has been taken up in almost all the districts. The total area in Karnataka under jasmine cultivation is 3634 ha with a total production of 20765 tonnes. The productivity is about 6 tonnes per hectare and value is 4268 lakhs. However, Bellary (1078 ha and 9234 tonnes) ranks first in the area and production followed by Koppal (96 ha and 1178 tonnes), Raichur (78 ha and 1092 tonnes) and Gulbarga (115 ha and 867 tonnes). Packaging is a tool for controlling flower quality in the distribution chain. Apart from preventing mechanical damage, the package serves as a barrier between the conditions inside and outside the package. It protects the flowers from unfavorable outside conditions and enables a micro-climate to develop inside the package. (Nowak et al., 1991).The growing demand and a limited shelf-life (12-30 h) of jasmine flowers require an appropriate packaging technology that would facilitate export of these flowers to both short and long distances without much loss in the post harvest quality (Singha et al.,2010).

The role attributed to $\mathrm{ABA}$ in petals is that of regulating the process of senescence. Endogenous levels of $\mathrm{ABA}$ rise as petals senescence, and exogenous treatment with ABA shortens the life of cut roses, thereby enhancing changes associated with senescence, such as changes in petal color and a decrease in the protein content (Hunter et al.,2004). Moreover, the amount of endo- genous ABA 
increases during senescence. Finally, imposi- tion of a water stress that increases the endogenous ABA level causes premature senescence of daylily petals. Abscisic acid (ABA) is a natural regulator of perianth senescence in flowers. The hormone is present in higher amounts in naturally senescing petals and in petals senescing prematurely in response to water stress (Wei et al. 2003).

ABA stimulates senescence and ABA levels increase during senescence. Abscisic acid is a possible candidate for a hor- monal trigger for death of flowers such as the daylily that do not respond to ethylene. There are reports that exogen- ously applied ABA accelerates leaf senescence. ABA causes a loss of differential membrane permeability, an increase in lipid peroxidation, induction of proteinase and ribonuclease activities, and induces a senescence-like mRNA profile in pre-senescent petal tissue (Huntera et al., 2004). Increased recognition of the importance of phenolic compounds in plant metabolic activities is well known. Polyphenols can be oxidised by peroxidase and Polyphenol oxidase. Phenols are the antioxidants that have the ability to protect plant tissue against oxidative damage (Schmitzer et al., 2009). The increasing demand for the fresh flowers as well as the need for the development of a reliable packaging technology for increasing the shelf-life of the jasmine flowers, thus the aim of this work was to study the endogenous variations of ABA content and phenolic content of different stages of storage of jasmine flowers during flower senescence .

\section{MATERIALS AND METHODS}

Study materials: Jasmine (J. sambac) flowers were chosen for the present study based on their availability and export demand. Fresh flowers of the above species were procured from flower growers of Raichur, brought to the laboratory and the flowers were sorted for experimental purpose. Unopened flower buds of uniform size were used for the study. The experiments were carried out in the Department of Processing and Food Engineering, College of Agricultural Engineering, UAS, Raichur, Karnataka. Raichur is situated on the latitude of $16^{\circ} 15 \square$ North, longitude of $77^{\circ} 21 \square$ East and at an elevation of 389 meters above mean sea level which is considered as North Eastern Dry Zone of Karnataka. India. Different packaging materials such as polyethylene (PE) and polypropylene (PP) were procured from M/s A1 Traders, Raichur. Polypropylene bags (PP), polyethylene (PE) of 200 gauge micron thickness, and $240 \mathrm{~mm} \times 140 \mathrm{~mm}$ size without vents were used for packaging of flowers. The selection of packaging material was confirmed by conducting several preliminary experiments for storage studies. Pretreatment of $4 \%$ boric acid for jasmine flowers was selected based on the best results obtained by the previous researchers. The sorted and uniform sized flower buds were dipped for 3 minutes in $4 \%$ boric acid solution and kept for 15 minutes for surface drying. Flowers of known weight $(25 \mathrm{~g}$ each) were packed in different packaging materials as per the treatments. The packaged flowers were kept for shelf-life evaluation in ambient condition. The treatment details are given below.

$\mathrm{T}_{1}$ - Open tray (control)

$\mathrm{T}_{2}$ - Pre-treatment with 4 per cent boric acid + open tray storage

$\mathrm{T}_{3}$ - Packaging in polyethylene (PE)

$\mathrm{T}_{4}$ - Pre-treatment with 4 per cent boric acid + packaging in polyethylene (PE)

$\mathrm{T}_{5}$ - Packaging in polypropylene (PP)

$\mathrm{T}_{6}$ - Pre-treatment with 4 per cent boric acid + packaging in polypropylene (PP)

Determination of abscisic acid in petals by microplate absorbance reader (ELISA): Abscisic acid is found in many plant tissues. Microplate absorbance reader (ELISA) used for determination of abscisic acid content in jasmine flowers. ABA was extracted from $0.11 \pm 2 \mathrm{mg}$ petals of jasmine flower samples with $1 \mathrm{ml}$ solution of 80 per cent acetone containing $10 \mathrm{mg}$ butylated hydroxytoluene and $50 \mathrm{mg}$ of citric acid. The petals were homogenized using the homogenizer and the samples were centrifuged at 11,000 rpm for $11 \mathrm{~min}$ and then the supernatant was lyophilized using the lyophilizer. The tracer solution, was prepared by adding $5 \mathrm{ml}$ of $1 \mathrm{X}$ TBS buffer to each ABA tracer vial and replaced with the cap and the contents were mixed by inverting the bottle several times and the solution were kept for 5 minutes before use afterwards prepare standards and the absorbance values were measured at $405 \mathrm{~nm}$ by using an enzyme-linked immunosorbent assay (ELISA) reader (Serrano et al., 2001) All determinations were carried out in dim light. The ABA levels were consistent with the dilution made and no interference from impurities was detected when ABA standards were added to diluted extracts. Results were expressed as pmol per gram fresh weight (pmol/g f.w.).

Determination of phenol content by using spectrophotometric method: The concentration of phenolics in plant extracts was determined using spectrophotometric method (singleton et al., 1999). Methanolic solution of the extract in the concentration of $1 \mathrm{mg} / \mathrm{ml}$ was used in the analysis. The reaction mixture was prepared by mixing $0.5 \mathrm{ml}$ of methanolic solution of extract, $2.5 \mathrm{ml}$ of $10 \%$ Folin-Ciocalteu's reagent dissolved in water and 2.5 $\mathrm{ml} 7.5 \%$ NaHCO3. Blank was concomitantly prepared, containing $0.5 \mathrm{ml}$ methanol, $2.5 \mathrm{ml} 10 \%$ FolinCiocalteu's reagent dissolved in water and $2.5 \mathrm{ml}$ of $7.5 \%$ of NaHCO3. The samples were thereafter incubated in a thermostat at $45{ }^{\circ} \mathrm{C}$ for $45 \mathrm{~min}$. The absorbance was determined using spectrophotometer at $\lambda \max =765 \mathrm{~nm}$. The samples were prepared in triplicate for each analysis and the mean value of absorbance was obtained. The same procedure was repeated for the standard solution of gallic acid and the calibration line was construed. Based on the measured absorbance, the concentration of phenolics was read $(\mathrm{mg} / \mathrm{ml})$ from the calibration line; then the content of phenolics in extracts Expressed as $\mu$ g equivalent of pyrocatechol/g of sample. 


\section{RESULTS AND DISCUSSION}

Quantification of abscisic acid in petals : Effect of pretreatment and packaging materials on abscisic acid (pmol/ g) content of the jasmine flowers was determined and data are presented in Table 1. Jasmine flower senescence depended on plant hormones such as abscisic acid (ABA), which increased during senescence. Among all the treatments used, abscisic acid content of jasmine flower was recorded maximum in open tray (control- $\mathrm{T}_{1}$ ) followed by pre-treated with 4 per cent boric acid and packed in open tray. After one day of packaging, maximum abscisic acid content of $5.71 \mathrm{pmol} / \mathrm{g}$ was observed in $\mathrm{T}_{1}$ open tray (control- $\mathrm{T}_{1}$ ). Treatment $\mathrm{T}_{4}$ (pre-treatment with $4 \%$ boric acid + packaging in polyethylene) and $\mathrm{T}_{6}$ (pre-treatment with $4 \%$ boric acid + packaging in polypropylene) recorded zero abscisic acid content after one day of packaging. On fourth day of storage, maximum abscisic acid content of $91.27 \mathrm{pmol} / \mathrm{g}$ was observed in $\mathrm{T}_{1}$ (control- $\mathrm{T}_{1}$ ) whereas minimum abscisic acid content of $34.16 \mathrm{pmol} / \mathrm{g}$ was observed in treatment $\mathrm{T}_{6}$ (pre-treatment with $4 \%$ boric acid + packaging in polyethylene), fol-

Table 1. Effect of pre-treatment and packaging materials on abscisic acid (pmol/g) of jasmine flowers.

\begin{tabular}{ccccc}
\hline \multicolumn{5}{c}{ Abscisic acid (pmol g $^{-1}$ ) } \\
\hline Treatments & Day 1 & Day 2 & Day 3 & Day 4 \\
\hline $\mathrm{T}_{1}$ & 5.71 & 36.27 & 67.83 & 91.27 \\
$\mathrm{~T}_{2}$ & 2.02 & 35.15 & 65.06 & 88.05 \\
$\mathrm{~T}_{3}$ & 0.23 & 20.34 & 37.94 & 52.28 \\
$\mathrm{~T}_{4}$ & 0.00 & 16.76 & 26.65 & 37.56 \\
$\mathrm{~T}_{5}$ & 0.20 & 18.06 & 32.94 & 45.46 \\
$\mathrm{~T}_{6}$ & 0.00 & 15.60 & 24.72 & 34.16 \\
$\mathrm{S.Em}$ & 0.04 & 0.49 & 0.90 & 1.22 \\
$\mathrm{CV}$ & 5.05 & 3.61 & 3.65 & 3.64 \\
$\mathrm{CD}(1 \%)$ & 0.17 & 2.13 & 3.87 & 5.27 \\
Factor & $\mathrm{S}$ & $\mathrm{S}$ & $\mathrm{S}$ & $\mathrm{S}$ \\
\hline
\end{tabular}

$\mathrm{T}_{1}$ - Open tray (control), $\mathrm{T}_{2}$ - Pre-treatment with 4 per cent boric acid + open tray storage, $T_{3}$ - Packaging in polyethylene (PE), $\mathrm{T}_{4}$ - Pre-treatment with 4 per cent boric acid + packaging in polyethylene, $\mathrm{T}_{5}$ - Packaging in polypropylene (PP), $\mathrm{T}_{6}$ - Pre-treatment with 4 per cent boric acid + packaging in polypropylene

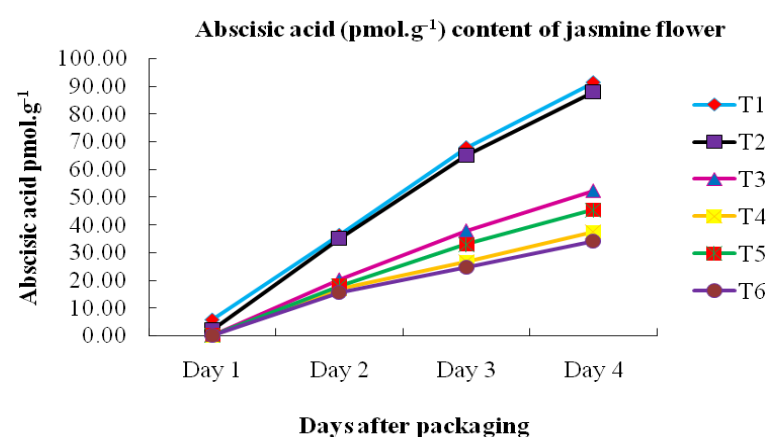

Fig. 1. Effect of pre-treatment and packaging materials abscisic acid ( $A B A)$ content in jasmine flower. lowed by $\mathrm{T}_{4}$ (pre-treatment with $4 \%$ boric acid + packaging in polypropylene) recorded abscisic acid content of $37.56 \mathrm{pmol} / \mathrm{g}$. Post harvest physiological analyses of senescence point to plant hormones play an important role in the promotion or inhibition of flower and leaf senescence. Among them, jasmine flower senescence depends on plant hormones such as abscisic acid (ABA), which increases during senescence. Among the treatments, abscisic acid content of jasmine flowers was recorded maximum in open tray (control- $\mathrm{T}_{1}$ ) is presented in Fig. 1. Similar results have been reported in rose, carnation, daffodil, iris, daylily and hibiscus in which ABA levels increased during senescence (Serrano et al., 2006; Trivellini et al., 2007 and Zhong and Ciafre, 2011). The ABA levels reached in boric acid-pre-treatment carnations were lower than that in control flowers, which might point to an inhibition of ABA biosynthesis by boric acid either directly or by some intermediate effect. In addition, spermidine levels were higher in the boric acid pre-treatment carnation flower; whereas the increase of ABA levels was lower (Serrano et al. 2006).

Table 2. Effect of pre-treatment and packaging materials on total phenols $(\mu \mathrm{g} / \mathrm{g})$ of jasmine flowers.

\begin{tabular}{ccccc}
\hline \multicolumn{5}{c}{ Total phenols $(\boldsymbol{\mu g} \mathbf{g} / \mathbf{g})$} \\
\hline Treatments & Day 1 & Day 2 & Day 3 & Day 4 \\
\hline $\mathrm{T}_{1}$ & 36.42 & 43.29 & 51.02 & 61.80 \\
$\mathrm{~T}_{2}$ & 34.01 & 41.20 & 49.45 & 60.00 \\
$\mathrm{~T}_{3}$ & 24.55 & 31.81 & 39.03 & 54.80 \\
$\mathrm{~T}_{4}$ & 23.66 & 29.15 & 34.98 & 51.03 \\
$\mathrm{~T}_{5}$ & 24.66 & 31.22 & 37.31 & 53.74 \\
$\mathrm{~T}_{6}$ & 22.68 & 27.52 & 32.21 & 50.90 \\
$\mathrm{S.Em}$ & 0.57 & 0.70 & 0.84 & 1.15 \\
$\mathrm{CV}$ & 3.57 & 3.57 & 3.57 & 3.61 \\
$\mathrm{CD}(1 \%)$ & 2.46 & 3.03 & 3.62 & 4.99 \\
Factor & $\mathrm{S}$ & $\mathrm{S}$ & $\mathrm{S}$ & $\mathrm{S}$ \\
\hline
\end{tabular}

$\mathrm{T}_{1}$ - Open tray (control), $\mathrm{T}_{2}$ - Pre-treatment with 4 per cent boric acid + open tray storage, $\mathrm{T}_{3}$ - Packaging in polyethylene $(\mathrm{PE}), \mathrm{T}_{4}$ - Pre-treatment with 4 per cent boric acid + packaging in polyethylene, $\mathrm{T}_{5}$ - Packaging in polypropylene (PP), $\mathrm{T}_{6}$ - Pre-treatment with 4 per cent boric acid + packaging in polypropylene

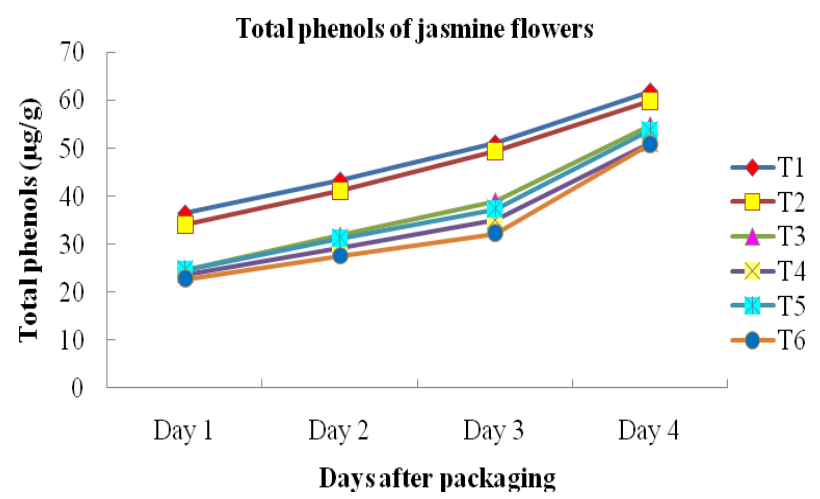

Fig. 2. Effect of pre-treatment and packaging materials on total phenols in jasmine flowers. 
Quantification of phenolic content : Table 2 shows the Effect of pre-treatment and packaging materials on total phenols of the jasmine flowers under ambient storage condition was determined. There was a significant difference in the phenols content of packaged, pre-treatment and non packaged (control) jasmine flower. After one day of packaging, open tray (control- $\mathrm{T}_{1}$ ) and Pre-treatment with 4 per cent boric acid + open tray storage $\left(\mathrm{T}_{2}\right)$ recorded maximum amount of total phenols with 36.42 and $34.01 \mu \mathrm{g} / \mathrm{g}$ respectively. The jasmine flowers Pretreatment with 4 per cent boric acid + packaging in polypropylene $\left(\mathrm{T}_{6}\right)$ and pre-treated with 4 per cent boric acid packed in polyethylene $\left(T_{4}\right)$ samples were found to have lower levels of total phenols $(22.68$ and $23.66 \mu \mathrm{g} / \mathrm{g})$. However, on $4^{\text {th }}$ day, there was a significant effect of packaging material and chemical treatment on the phenol content of the flowers was noticed. The jasmine flowers Pre-treatment with 4 per cent boric acid + packaging in polypropylene $\left(T_{6}\right)$ and pre-treated with 4 per cent boric acid packed in polyethylene $\left(\mathrm{T}_{4}\right)$ samples recorded significantly lower levels of total phenols (50.90 and $51.03 \mu \mathrm{g} / \mathrm{g}$ ) of packing, respectively). The flowers placed in open tray (control- $\mathrm{T}_{1}$ ) and Pre-treatment with 4 per cent boric acid + open tray storage $\left(T_{2}\right)$ were recorded higher total phenols content of 61.80 and $60.00 \mu \mathrm{g} / \mathrm{g}$ of sample, respectively is presented in Fig. 2. reported by Karuppaiah et al. (2006) and Nirmala and Reddy (1992) in J. sambac.

\section{Conclusion}

The major conclusions drawn from the present investigation on ABA content and Phenolic Content Changes during storage of jasmine flower (Jasminum sambac) are as follows: Among all the treatments, the jasmine flowers pre-treated with 4 per cent boric acid and packed in 200 gauge polyethylene (PE) and 200 gauge polypropylene (PP) maintained minimum abscisic acid (ABA) levels in petals resulting in maximum shelf-life. Phenol content of jasmine flowers increased rapidly during storage. After four days of packaging, open tray (control) samples recorded maximum total phenolic content of $61.8 \mu \mathrm{g} / \mathrm{g}$. Pre -treated with 4 per cent boric acid and packed in polypropylene $\left(T_{6}\right)$ samples were found to have lower levels of total phenols of $50.90 \mu \mathrm{g} / \mathrm{g}$ respectively. Jasmine flower pre-treated with 4 per cent boric acid and packed in $\mathrm{PE}$ (T4) and PP (T6) recorded minimum abscisic acid (ABA) levels in petals and a lower level of total phenols. As the flowers are highly perishable there is a need for the development of a reliable packaging technology for increasing the shelf-life of the flowers. Basically, the post-harvest life of flowers can be enhanced by delaying the senescence of flowers after packaging. Hence, the focus of the present investigation was to study the effect of pretreatment and suitability of packaging material that would enhance the shelf-life of jasmine flowers including reduction in physiological activities with minimal deterioration in post-harvest quality of the flowers.

\section{ACKNOWLEDGEMENTS}

We wish to thank Dr. I. Shanker Goud Associate Director of Research Main Agricultural Research Station and Dr. M. Bheemanna Biological control Laboratory University of Agricultural Sciences Raichur for their kind encouragement and laboratory facilities and department of processing and food engineering, CAE, UAS, Raichur.

\section{REFERENCES}

Dadlani, N. K., 2004, Cut flower production in Asia. Division of Floriculture, Indian Agricultural Research Institute, New Delhi, India

Huntera, D.A., Ferranteb A., Vernierib, P. and Reida. M.S., 2004. Role of abscisic acid in perianth senescence of daffodil (Narcissus pseudonarcissus 'Dutch Master'). Physiologia plantarum .121: 313-321.

Karuppaiah P, Kumar S R and Rajkumar M. 2006. Effect of different packages on the post harvest behaviour and shelf-life of jasmine (Jasminum sambac). Int. J. Agric. Sci. 2: 447-449.

Kiritikar K R and Basu B D., 2003. Indian Medicinal Plants with Illustrations.Oriental Enterprises. 7 : 2093-2096.

Nirmala S and Reddy T V. 1992. Shelf-life of jasmine (Jasminum sambac) flowers as influenced by packaging and ventilation. Mysore. J. Agric. Sci. 27: 272-276.

Nowak J, Goszczynska D M and Rudnicki R M. 1991. Storage of cut flowers and ornamental plants: present status and future prospects. Post harvest News Inf. 2: 255-260.

Schmitzer V, Veberic, R., Osterc, G., and Stampar,F, 2009. Changes in the Phenolic Concentration during Flower Development of Rose 'KORcrisett' J. Amer. Soc. Hort. Sci. 134(5):491-496.

Serrano, M, D., Martinez-Romero, F., Guillen, S., Castillo and Valero, D., 2006, Maintenance of broccoli quality and functional properties during cold storage as affected by modified atmosphere packaging. Post harvet Biol. Technol., 39: 61-68.

Serrano, M., Amoros, A., Pretel, M. T., Madrid, M. C. M., Romojaro, F., 2001, Preservative solutions containing boric acid delay senescence of carnation flowers. Post harvet Biol. Technol., 23: 133-142.

Singha, A., Dhaduk, B. K. and Ahlawat, T., 2010, Storage of jasmine (Jasminum sambac) in passive MAP. Post harvest Qual. Ornament. Pl., 13: 171-181.

Singleton, V.L., Orthofer, R., Lamuela-Raventos, R.M. 1999. Analysis of total phenols and other oxidation substrates and antioxidants by means of Folin-Ciocalteu reagent. Methods Enzymol. 299, 152-178.

Trivellini, A., Vernieri, P., Ferrante, A. and Serra, G., 2007, Physiological characterization of flower senescence in long life and ephemeral hibiscus (Hibiscus rosa-sinensis L.). Acta Hort., 755: 457-464.

Wei, Z., Zhang, H., Gu Z.P, Zhang J.J., 2003, Cause of senescence of nine sorts of flowers. Acta Bot Sinica., 33: 429-436

Zhong, Y. and Ciafre, C., 2011, Role of ABA in ethyleneindependent Iris flower senescence. Int.Conf. on Food Engng. Biotech., IPCBEE, IACSIT Press, Singapore Vol. 9. 